\title{
Carbon and Cost Critical Elements of Buildings: A COMPARATIVE ANALYSIS OF TWO OFFICE BUILDINGS
}

\author{
Michele Florencia Victoria \\ The Scott Sutherland School Of Architecture And Built Environment, Robert \\ Gordon University, Aberdeen, UK \\ Srinath Perera \\ School Of Computing Engineering \& Mathematics, Western Sydney University, \\ Sydney, Australia, \\ Alan Davies and Nirodha Fernando \\ Department Of Architecture and Built Environment, Northumbria University, \\ Newcastle Upon Tyne, UK
}

\begin{abstract}
Purpose: The aim of this paper is to identify and compare cost and carbon critical elements of two office buildings and to propose an early design stage cost and carbon control strategy to achieve an optimum balance between building Capital Cost (CC) and Embodied Carbon (EC).

Design/methodology/approach: Case study approach was employed to identify cost and carbon critical elements of two office buildings as it allows an in-depth and holistic investigation. Elemental estimates of $\mathrm{CC}$ and EC were prepared from BoQs of the two office buildings by obtaining rates from the UK Building Blackbook. Pareto Principle (80:20 rule) was used to identify carbon and cost critical elements of the two buildings and the significance hierarchies of building elements were compared.

Findings: Substructure, Frame and Services were identified as both carbon and cost critical elements responsible for more than $70 \%$ of the total CC and EC in both buildings. Stairs and Ramps, Internal Doors and Fittings, Furnishings and Equipment were identified to be the least carbon and cost significant elements contributing less than $2 \%$ of total $\mathrm{CC}$ and EC in both buildings. The hierarchy of cost and carbon significance varies between buildings due to the difference in the specification and design.

Originality/value: The increasing significance of dual currency (cost and carbon) demands cost and carbon management during the early stages of project. Hence, this paper suggests that focusing on carbon and cost intensive building elements is a way forward to keep both cost and carbon under control during the early stages of projects.
\end{abstract}

Keywords: Carbon Hotspots, Capital Cost, Cost Hotspots, Embodied Carbon, Office Buildings.

Article type: Research paper

\section{INTRODUCTION}

Carbon management in built environment is imperative to tackle the global climate change by reducing Greenhouse Gases (GHGs). Even though carbon (implies GHG) emitted during the operation of buildings (Operational Carbon - OC) is managed through statutory benchmarks, carbon emitted during the production, maintenance and demolition of buildings (Embodied Carbon - EC) is not regulated. However, EC management is becoming prevalent now. EC cannot be managed unless it is measured and EC databases are fundamental building blocks of EC estimating. A range of embodied carbon inventories are available to facilitate EC estimating at different stages of a building's life cycle including material production, construction, use and end-of life stages. Inventory of Energy and Carbon (ICE) developed by Hammond and Jones (2011) is a cradle-to-gate (or production stage) inventory which assist is estimating EC of a building during the production stages. The UK Building Blackbook is 
another data source developed using ICE and data from manufactures and suppliers, which assist in the production stage EC estimating. Construction and in-use EC are project specific as it depends on the method of construction and the type of fuel used, hence, there are carbon conversion factors for fuels to the calculated carbon footprint of business operations. Department for Environment Food and Rural Affairs (2015) in the UK maintains the repository of carbon conversion factors. Similarly, end-of-life emissions are project specific and fuel conversion factors can be used to estimate EC during this stage too while a dataset developed by PE International assist in the end-of-life EC calculations for common framing materials. In addition, $\mathrm{GaBi}$ (developed by PE Internationals) and ecoinvent (developed by the Centre for Life Cycle Inventories) are international life cycle inventories, which are conversant databases but are not freely accessible as the other databases mentioned above. Apart from these, businesses provide access to their data by integrating their data in to third-party databases or national databases such as WRAP Embodied Carbon database in the UK.

The existence of a range of EC databases with different source data makes EC estimating non-uniform. Clark (2013) noted difference in the EC values estimated by different estimators, for the same building. The commonly identified factors affecting EC measurements include the system boundary of the analysis, the method of estimating, underlying assumptions, data sources used and element classification (Dixit et al., 2010, Clark, 2013, Ekundayo et al., 2012, Victoria et al. 2015a). The most problematic factor of the five is the underlying assumptions of the estimate, which are subjective to the estimator and cannot be standardised. Hence, these factors make it challenging to compare studies conducted at different parts of the world at different times. In fact, existing EC databases facilitates EC estimating during the detail stages of design while the reduction potential of $\mathrm{EC}$ is claimed to be high during the early stages of projects (RICS, 2014) similar to CC. Hence, there is a need for EC estimating and control mechanisms during the early stages of design. RICS (2014) suggests that focusing on intensive emission sources is a good approach to keep EC under control during the early stages of design, which are referred to as the carbon critical elements or the 'carbon hotspots' in this context. However, empirical research that explore EC datasets and control strategies for early design stages are limited. Accordingly, this paper proposes a method that can facilitate early stage EC estimating and controlling by focusing on carbon critical elements by employing two case study buildings. Furthermore, cost and carbon critical elements of the case study buildings were compared due to the increasing attention to both cost and carbon, which are referred to as the dual currency of construction projects (Ashworth and Perera, 2015; Victoria et al. 2015a).

\section{CARbon Hotspots}

RICS (2014) defines 'carbon hotspots' as the carbon significant aspect of the project which can be building elements or other aspects in supply chain. Ease of measurability and reduction possibility are two key features of carbon hotspots (RICS, 2014). Carbon hotspots may vary from one building to the other depending on the type or the function of the building (Ashworth and Perera, 2015). Monahan and Powell (2011) highlighted the importance of identifying hotspots in buildings by modelling a two storied residential building (in the UK) in three different scenarios, (1) timber frame and larch cladding, (2) timber frame and brick cladding and (3)conventional masonry and cavity wall. Substructure and external walls were identified as carbon hotspots of the residential building and the potential for carbon reduction through alternative designs was highlighted. Similarly, Shafiq et al. (2015) studied a twostoried office building in Malaysia by modelling six different scenarios for structural composition. Different grades or classes of concrete and steel were combined to generated different composition that resulted in different material quantities producing varying EC impacts. Only a few elements were studied including foundation, beams, slabs, columns and staircases, which can be related to Substructure, Frame, Upper Floors and Stairs according to New Rules of Measurement (NRM) element classification. Shafiq et al. (2015) found that it was possible to reduce up to $31 \%$ of EC by using different classes of concrete and steel to meet the given design criteria.

EC studies in different types of buildings highlighted above (Monahan \& Powell, 2011; Shafiq et al, 2015) have different focus and hence, limit the analysis to a few elements. However, analysis of the whole building elements will provide a holistic picture on the EC contribution of each element and will 
unfold potential areas of carbon reduction. Table 1 presents a compilation of low, medium and highrise office buildings case studies in the UK. Superstructure is unanimously the predominant carbon hotspot while the contribution increases with the height of the building. Substructure EC is generally one fourth of the total EC though the contribution becomes significant with the inclusion of basements (see, the case study of Victoria et al., 2015). Finishes ranges from 1\% to 15\% highlighting the wavering nature of the element. Most case studies have not included Fittings EC while WRAP case study suggests that it can contribute up to $13 \%$ of the total EC. The contribution of Services EC seems to be underrepresented in the presented case studies as Services are said to be accounting for 10-25\% of total EC (Hitchin, 2013; RICS, 2014). The identified low contribution of Services could be attributable to non-inclusion of all services as is evident in the case study reported by Victoria et al., (2015b) which covers only Disposal, Sanitary, Water and Lift installations. Accordingly, the comparison of case studies suggests that hotspots can vary for different classes of building such as low, medium and highrise and no robust knowledge exist concerning the carbon hotspots of different types and classes of buildings.

Table 1: Case studies of office buildings from the literature

\begin{tabular}{|c|c|c|c|c|c|c|c|}
\hline & \multicolumn{3}{|c|}{ Halcrow Yolles (2010) } & \multirow[t]{2}{*}{ WRAP } & \multirow{2}{*}{$\begin{array}{l}\text { Victoria } \\
\text { et al. } \\
\text { (2015) }\end{array}$} & \multirow{2}{*}{$\begin{array}{c}\text { Sturgis } \\
\text { Associates } \\
(\mathbf{2 0 1 0}) \\
\text { Ropemaker } \\
\text { Place }\end{array}$} & \multirow{2}{*}{$\begin{array}{c}\text { RICS } \\
\text { (2012) } \\
\text { Leadenhall }\end{array}$} \\
\hline & Okehampton & Pool & Brunel & & & & \\
\hline $\operatorname{GIFA}\left(\mathrm{m}^{2}\right)$ & 1,140 & 3,441 & 2,341 & Unknown & 33,663 & 56,020 & 86,450 \\
\hline Storeys (No) & 1 & 2 & 2 & $\begin{array}{l}\text { Medium- } \\
\text { rise }\end{array}$ & 18 & 21 & 51 \\
\hline Basements (No) & 0 & 0 & 0 & 0 & 2 & 0 & 0 \\
\hline Substructure & $30 \%$ & $22 \%$ & $20 \%$ & $16 \%$ & $44 \%$ & $25 \%$ & $25 \%$ \\
\hline Superstructure & $52 \%$ & $62 \%$ & $72 \%$ & $57 \%$ & $55 \%$ & $60 \%$ & $74 \%$ \\
\hline Internal Finishes & $15 \%$ & $12 \%$ & $6 \%$ & $10 \%$ & $1 \%$ & $10 \%$ & $1 \%$ \\
\hline $\begin{array}{l}\text { Fittings, } \\
\text { Furnishings \& } \\
\text { Equipment }\end{array}$ & - & - & - & $13 \%$ & $0.1 \%$ & - & - \\
\hline Services & $3 \%$ & $4 \%$ & $2 \%$ & $3 \%$ & $1 \%$ & $5 \%$ & - \\
\hline
\end{tabular}

It is expected that EC planning will be embedded with cost planning process in the future with the increasing significance of dual currency of construction projects (Ashworth and Perera, 2015). However, research focusing on EC and CC relationships are limited. Langston and Langston (2008) analysed the relationship between initial embodied energy and CC of buildings in Australia and found a strong correlation at the project level and the relationship was insignificant at the elemental and material levels. However, the sample consisting of different types of buildings was a drawback of the study of Langston and Langston (2008) as carbon hotspots may vary for different types of the buildings resulting in different correlations. Further, embodied energy and carbon are not interchangeable as the material production process might emit or sequester carbon (Hammond and Jones, 2011, Brandt, 2012, Lélé, 1991). Hence, differing relationships might exist between EC and CC. This identified gap in the literature makes the case for exploring and comparing carbon and cost critical elements to contribute to the state-of-the art literature and to improve the early design stage decision-making of industry practitioners.

\section{RESEARCH METHOD}

This investigation can take either quantitative or qualitative form. Qualitative methods allow micro investigation of a problem and could possibly lead to the development of theories and hypotheses that can be tested through quantitative methods. Yin (2014) suggests that experiments, history and case 
studies are appropriate to deal with 'how' and 'why' form of research questions while surveys and archival analysis are good at answering 'who', 'what', 'where', 'how many', 'how much' types of research questions. This study seeks to answer 'what are carbon critical elements and how they compares to cost critical elements?'. According to Yin (2014), the proposed methods to answer the above research questions include surveys and archival analysis. However, this is a relatively new area of research and no past studies have empirically identified cost and carbon critical elements of buildings. Hence, case study approach was selected to study a few buildings in-depth (Fellows and Lieu, 2003) and holistically (Harling, 2002) which can lead to the development of hypothesis (for example, $20 \%$ of buildings elements are responsible for $80 \%$ of EC) that can be tested with a larger sample of data. Accordingly, two buildings (two case studies) were employed to investigate cost and carbon critical elements of those buildings and to study their interactions. Individual building selected as a case in the study.

Case study buildings were selected using purposive sampling technique from a small dataset obtained from construction consultancy practices in the UK. Homogeneity of design parameters was the key selection criteria as cost and carbon intensity varies with the function and class of buildings (for instance, function encompasses residential, offices, warehouse and the like and class encompasses low, medium and high-rise buildings). Hence, both buildings were offices and have similar design parameters in terms of GIFA, building height, façade area and building perimeter. Building A is $11,320 \mathrm{~m}^{2}$ and eight (8) storied with a basement; Building B is $15,120 \mathrm{~m}^{2}$ and seven (7) storied with two basements. Both buildings have a hybrid frame with raft foundation comprising concrete flat roof. Façade of Building A is made of pre-engineered stone concrete and glass while Building B has a curtain wall system. Both buildings have a combination of brick, block, dry lined and glazed internal partitions, finished with moderate types of finishes and accommodate highly sophisticated services including Building Management System (BMS).

EC and CC estimates were prepared using unpriced Bills of Quantities (BoQ) and the UK Building Blackbook (Franklin and Andrews, 2011). In addition, data were obtained from manufacturers and suppliers when EC and CC rates were not present in the Blackbook. The UK Building Blackbook is a data book containing itemised CC and EC rates in accordance with the Standard Method of Measurements which was developed using the EC data from ICE. However, Blackbook data have a base date of $20102 \mathrm{Q}$ (price index - 218) and a location index of 100. Subsequently, costs were updated to 2016 1Q (price index - 276) and the location was index kept unchanged. Even though adjustments for CC was made, adjustments for EC was not made as EC is affected by processes (in this context process include manufacturing process of building materials). Therefore, an adjustment to EC data is not required unless the process is changed. This leads to a crucial assumption in EC calculations that the manufacturing process of materials has not changed radically.

Two key problems encountered in the data collection were lack of detailed measurements (in BoQs) and lack of EC and CC rates (in the UK Building Blackbook) for building services. The problem of lack of EC and CC rates were overcome by obtaining CC benchmarks from Spon's price book (Davis Langdon Consultancy, 2014) and EC benchmarks developed from a specific dataset (consists of EC data of 28 offices in the UK) obtained from a UK consultancy practice. Consequently, EC and CC of services for the case study buildings were estimated using the EC and CC benchmarks to prepare a complete estimate and to present a holistic analysis of case study buildings. The CC and EC rates used for the other types of services are roughly $£ 371$ to $£ 386$ per m${ }^{2}$ GIFA and $163 \mathrm{kgCO}_{2}$ per m $\mathrm{m}^{2}$ GIFA respectively. It should be noted that the estimates are subjective to the five key factors introduced in the literature as it covers only cradle-to-gate (production) EC; used manual estimating relying on the measurements obtained from consultancy practices; involves assumptions on missing pricing information; the UK Building Blackbook was the major source of data used; and followed NRM element classification.

The next step in the investigation is to identify cost and carbon critical elements of the case study buildings by employing a structure approach. Munns and Al-Haimus (2000) highlighted that seminal texts in the cost management literature (Ashworth and Perera, 2015, Seeley, 1996, Ashworth and Skitmore, 1983) recognise the applicability of Pareto Principle to identify cost significant items in 
buildings. The works of Munns and Al-Haimus (2000) and Tas and Yaman (2005) are examples of embracing 80:20 Pareto Principle to identify cost significant items in a BoQ. Hence, it is evident that 80:20 Pareto Principle is widely accepted as the popular method of identifying cost significant items in a building. Pareto Principle defines that $80 \%$ of the results (or consequences) are attributable to $20 \%$ of the causes, which demonstrates unequal relationship between the inputs and the outputs (Koch, 2011). Accordingly, it can be hypothesised that $80 \%$ of the EC of a building is caused by $20 \%$ of its elements. However, BoQ items have to be grouped (to minimise complexity by reducing the number of items) either by work packages (trades) or functional elements to identify the cost or carbon significant items as done in previous studies (See, Munns and Al-Haimus, 2000, Tas and Yaman, 2005).

Accordingly, BoQ items were grouped by elements (to study the cost and carbon significance of building elements irrespective of trades) in accordance with the NRM elements classification system (RICS, 2012) which is the latest measurement standard prevailing in the UK. Sum total of EC and CC of each element group were obtained and the element groups were arranged in a descending order of their group totals. Cumulative percentage of the element group totals were calculated to identify the elements contributing up to $80 \%$ of the total EC and total CC separately for each building, which are referred to as the carbon or cost critical elements or the hotspots of the buildings.

\section{Data ANALYSIS AND DISCUSSION}

The estimated total CC of Building A was $£ 14,157,600$ and Building B was $£ 15,768,900$; the estimated $\mathrm{EC}$ of Building A was $8,806,100 \mathrm{kgCO}_{2}$ and Building $\mathrm{B}$ was $11,574,500 \mathrm{kgCO}_{2}$. The $\mathrm{CC}$ and $\mathrm{EC}$ breakdown of the main elements of Building A and Building B are presented in Figure 1. Accordingly, Superstructure of Building A contributes almost equally towards CC (44\%) and EC (49\%) while Superstructure is the predominant carbon and cost significant element (hotspot) among others in Building A. Substructure is the second most significant carbon hotspot and the EC of the Substructure $(23 \%)$ is as twice as its CC (10\%). Services are the second most significant cost hotspot in Building A, contributing up to $36 \%$ while Services $(22.8 \%)$ and Substructure $(23.1 \%)$ contribute almost equally towards the EC of Building A. Internal Finishes contribute up to $10 \%$ and $5 \%$ towards CC and EC, respectively. Fittings, Furnishing and Equipment are the least significant in terms of both CC and EC contributing less than $1 \%$. Similar to Building A, Superstructure of Building B contributes almost equally towards CC (35\%) and EC (39\%) though the contribution of Superstructure towards CC and EC in Building B is lower than the contribution of Building A. Substructure CC of Building B is as twice as the $\mathrm{CC}$ of Building A (the same is true for EC). This is mainly due to Building B having two (2) basements. Further, the EC of Substructure is almost equal to the EC of Superstructure of Building $\mathrm{B}$, which signifies the importance of Substructure design. EC of Services is identified as the third important contributor towards the total EC of Building B while Services are the highest CC contributor of Building B. The contribution of Internal Finishes towards the total CC and EC of Building B are insignificant and almost equal whereas the $\mathrm{CC}$ and $\mathrm{EC}$ of Fittings, Furnishing and Equipment of Building B are negligible similar to Building A. 


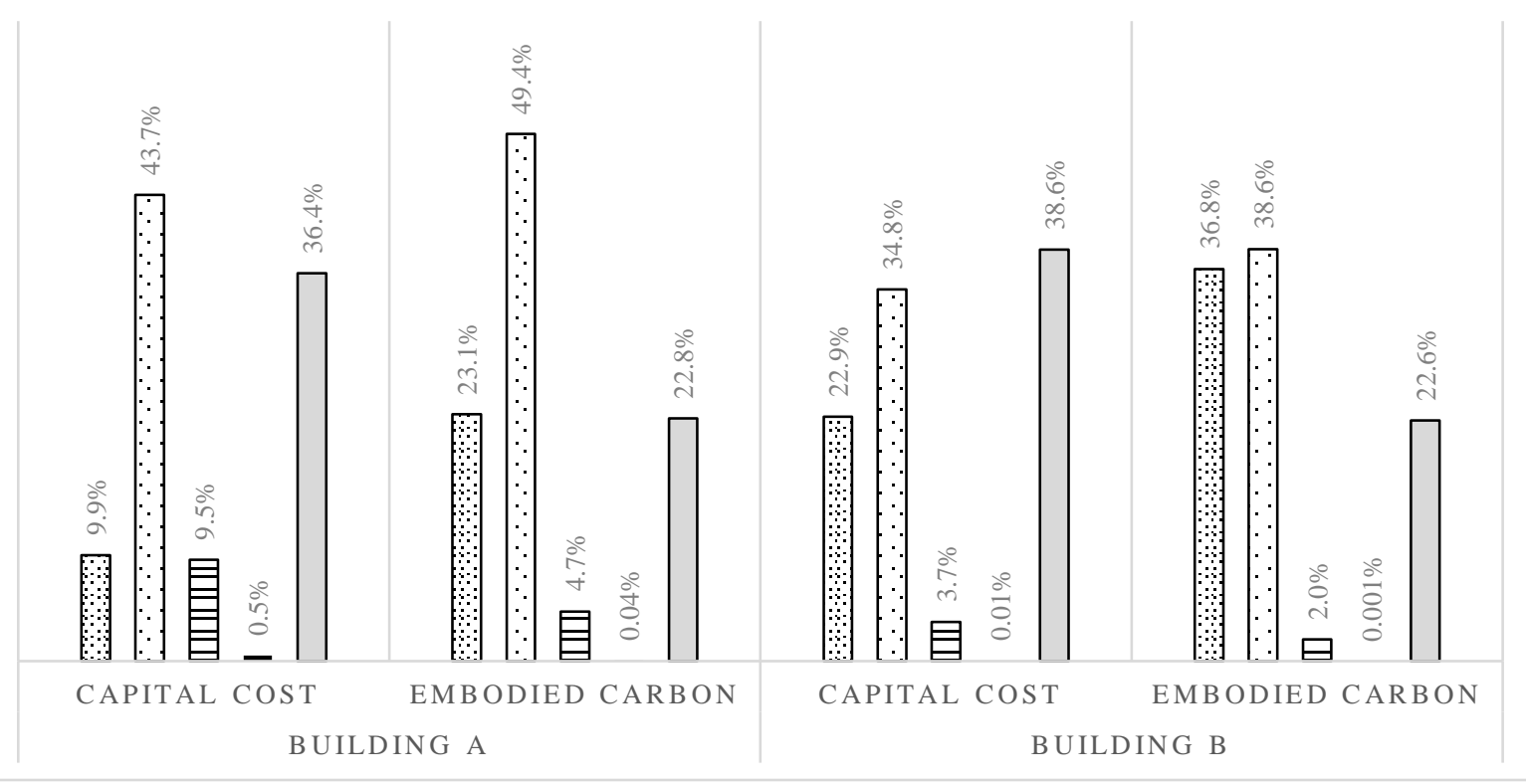

Figure 1: CC and EC contribution by elements - Building A and Building B

Similar and differing patterns were noticed when comparing the study findings with case studies presented in Table 1. Substructure EC of Building A is about a fourth of its total EC while Building B is more than a third of its total EC due to two basements, which validates the literature findings. Superstructure EC of both buildings are lower than the literature figures due to the inclusion of Fittings and Services in the analysis, which demonstrates the superiority of holistic analysis. Finishes EC is neither higher nor lower than the figures presented in the literature. EC of Fittings are negligible similar to the findings of Victoria et al. (2015b) while Services accounts for approximately $23 \%$ in both case study buildings which is higher the literature figures and are in-line with the percentage proposed by Hitchin (2013) and RICS, (2014).

Building A and B have almost similar group CC and EC elemental profiles. Superstructure is identified as the most cost and carbon significant element in Building A, while Services is identified as the most cost significant and Superstructure is identified as the most carbon significant in Building B. Hence, in both the cases, Superstructure is identified as the most carbon significant element while there is a difference in cost significance. Findings also suggested that having an additional basement in a building can increase EC significantly, making Substructure as EC intensive as Superstructure. Even though the $\mathrm{CC}$ and EC of Internal Finishes do not highly influence the total CC and EC of Buildings A and B (as both buildings have moderate finishes), it can be a significant contributor in high-end office buildings with luxury finishes. Furthermore, the contribution of Fittings, Furnishing and Equipment towards the total $\mathrm{CC}$ and $\mathrm{EC}$ are almost negligible in both cases.

Table 2: Hierarchy of carbon and cost significance of building elements of the case study buildings

\begin{tabular}{|l|l|l|l|}
\hline \multicolumn{2}{|c|}{ Cost Significance Hierarchy } & \multicolumn{2}{c|}{ Carbon Significance Hierarchy } \\
\hline Building A & \multicolumn{1}{c|}{ Building B } & \multicolumn{1}{c|}{ Building A } & \multicolumn{1}{c|}{ Building B } \\
\hline Services & Services & Frame & Substructure \\
\hline Frame & Substructure & Substructure & Services \\
\hline Substructure & Frame & Services & Frame \\
\hline $\begin{array}{l}\text { External Walls (Incl. } \\
\text { Windows and External }\end{array}$ & External Walls (Incl. & Upper Floors & Upper Floors \\
Doors) & Windows and External & & \\
\hline
\end{tabular}




\begin{tabular}{|l|l|l|l|}
\hline Ceiling Finishes & $\begin{array}{l}\text { Internal Walls and } \\
\text { Partitions }\end{array}$ & $\begin{array}{l}\text { Internal Walls and } \\
\text { Partitions }\end{array}$ & $\begin{array}{l}\text { External Walls (Incl. } \\
\text { Windows and External } \\
\text { Doors) }\end{array}$ \\
\hline Upper Floors & Upper Floors & $\begin{array}{l}\text { External Walls (Incl. } \\
\text { Windows and External } \\
\text { Doors }\end{array}$ & Roof \\
\hline $\begin{array}{l}\text { Internal Walls and } \\
\text { Partitions }\end{array}$ & Roof & Ceiling Finishes & $\begin{array}{l}\text { Internal Walls and } \\
\text { Partitions }\end{array}$ \\
\hline Floor Finishes & Floor Finishes & Roof & Floor Finishes \\
\hline Roof & Ceiling Finishes & Floor Finishes & Wall Finishes \\
\hline Wall Finishes & Wall Finishes & Wall Finishes & Ceiling Finishes \\
\hline $\begin{array}{l}\text { Fittings, Furnishings and } \\
\text { Equipment }\end{array}$ & Internal Doors & Stairs and Ramps & Stairs and Ramps \\
\hline Stairs and Ramps & Stairs and Ramps & Internal Doors & Internal Doors \\
\hline Internal Doors & $\begin{array}{l}\text { Fittings, Furnishings and } \\
\text { Equipment }\end{array}$ & $\begin{array}{l}\text { Fittings, Furnishings and } \\
\text { Equipment }\end{array}$ & $\begin{array}{l}\text { Fittings, Furnishings } \\
\text { and Equipment }\end{array}$ \\
\hline
\end{tabular}

Table 2 presents the hierarchy of cost and carbon significance of building elements of two case studies.. The elements that are coloured in greyscale are the elements that contribute up to $80 \%$ of the CC and $\mathrm{EC}$ of the buildings and identified as cost or carbon hotspots. According to the significance analysis, cost hotspots of Building A and Building B are almost the same except for Ceiling Finishes, which has been identified as a cost hotspot in Building A. Services is identified as the most cost significant building elements in both buildings while the cost significance of Substructure and Frame is interchanged. External Walls including Windows and External Doors are identified as the third most cost significant element in case study buildings. However, the cost significance of the rest of the elements vary between the buildings. On the other hand, the same four elements are identified as carbon hotspots in both buildings including Substructure, Frame, Upper Floors and Services, though, the carbon significance of elements wavers between the two. Similarly, carbon significance hierarchy of the rest of the elements vary though the three least carbon significant elements in both buildings are Stairs and Ramps, Internal Doors and Fittings, Furnishings and Equipment in the same order.

In addition, Substructure, Frame and Services are identified as both cost and carbon hotspots in both buildings, capturing the first three positions in the cost and carbon significance hierarchy. External walls are identified as cost significant while Upper Floors are identified as carbon significant in both case study buildings. The comparison of buildings showcases the elements that are both cost and carbon hotspots (Substructure, Frame and Services) and the elements that are almost insignificant (such as Stairs and Ramps, Internal Doors and Fittings, Furnishings and Equipment which captures the last three positions in the cost and carbon significance hierarchy and contributes less than $2 \%$ towards total CC and EC). However, there are elements that lie between these two categories, which are vague in nature and have the potential to become a cost or carbon hotspot such as, Upper Floor, External Walls, Windows and External Doors, Roof, Internal Walls and Partitions, Wall Finishes, Floor Finishes and Ceiling Finishes. These elements require special attention during the design phase though more attention should be given to the design of elements that are identified as both cost and carbon hotspots (Substructure, Frame and Services are identified as both carbon and cost hotspots in the case study buildings).

Furthermore, CC per GIFA and EC per GIFA (referred to as 'element rates') are also calculated for individual elements of Building $\mathrm{A}$ and Building $\mathrm{B}$ to get insights in to the findings and presented in Table 3. Even though CC and EC demonstrate a similar patter between case study buildings when analysing at main elemental level, differences were noticed at individual elemental level. Clearly, Services is the most cost significant hotspot in both buildings and has similar element rates in Buildings $\mathrm{A}$ and B. However, Substructure element CC rate is doubled in Building B due to an additional basement in the building while Frame element $\mathrm{CC}$ rate is almost reduced to half in Building B compared to Building A which almost compensates for the increased cost in Substructure. Further, element CC rates of External Walls, Internal Walls and Partitions, Roof and Internal Doors are very similar in both 
buildings while difference in element $\mathrm{CC}$ rates can be noticed for the remaining elements due to the difference in element specifications. On the other hand, similar element EC rates were noticed in Roof, Internal Doors, Wall Finishes and Services while the element EC rates of other elements vary.

Table 3: Comparison of CC per GIFA and EC per GIFA of building elements of case study buildings

\begin{tabular}{|l|r|r|r|r|}
\hline \multirow{2}{*}{ Building Elements } & \multicolumn{2}{|c|}{ CC per GIFA $\left(\mathfrak{f} / \mathbf{m}^{2}\right)$} & \multicolumn{2}{c|}{ EC per GIFA $\left(\mathbf{k g C O}_{2} / \mathbf{m}^{2}\right)$} \\
\cline { 2 - 5 } & \multicolumn{1}{|c|}{ Building A } & \multicolumn{1}{c|}{ Building B } & \multicolumn{1}{c|}{ Building A } & Building B \\
\hline Substructure & 124.1 & 239.1 & 179.9 & 281.5 \\
\hline Frame & 318.7 & 175.8 & 203.9 & 143.9 \\
\hline Upper Floors & 50.9 & 23.9 & 97.5 & 63.0 \\
\hline Roof & 24.3 & 20.9 & 16.4 & 18.2 \\
\hline Stairs and Ramps & 6.1 & 0.9 & 4.7 & 1.0 \\
\hline $\begin{array}{l}\text { External Walls (Incl. Windows } \\
\text { and External Doors) }\end{array}$ & 107.5 & 107.7 & 27.3 & 59.4 \\
\hline Internal Walls \& Partitions & 33.2 & 28.3 & 34.1 & 9.5 \\
\hline Internal Doors & 5.7 & 6.0 & 0.7 & 0.7 \\
\hline Wall Finishes & 21.4 & 11.4 & 5.3 & 4.1 \\
\hline Floor Finishes & 29.9 & 14.0 & 13.8 & 8.0 \\
\hline Ceiling Finishes & 67.6 & 12.7 & 17.2 & 3.4 \\
\hline Fittings, Furnishings \& & & & & \\
Equipment & 6.4 & 0.1 & 0.3 & 0.1 \\
\hline Services & 454.9 & 402.1 & 177.0 & 172.9 \\
\hline
\end{tabular}

In addition, Table 3 highlights the magnitude of difference in CC and EC rates. For instance, External Walls are found to be cost significant while EC contribution of the same is very low. The reason for this could be timber used in windows and external doors where $\mathrm{CC}$ of timber is high while EC of timber is very low resulting in the identified difference in rates. This implies that cost and carbon significance hierarchies should be complemented by elemental EC and CC benchmarks to manage dual currency effectively during the early design stages. Hence, specification of building elements plays a major role in dictating $\mathrm{CC}$ and EC of buildings and their cost and carbon significance hierarchies.

\section{Conclusions}

The need to manage EC is at the forefront of the climate change propaganda for built environment. Hence, this paper proposes an approach to control EC and CC (the dual currency) during the early stages of design by studying two office building in the UK. Pareto principle (80:20 rule) was adopted to identify cost and carbon critical elements of the case study buildings - elements that are responsible for $80 \%$ of EC or CC of the building. Substructure, Frame and Services were identified as both cost and carbon hotspots in both buildings responsible for more than $70 \%$ of the total CC and EC in both buildings. Likewise, Stairs and Ramps, Internal Doors and Fittings, Furnishings and Equipment were identified as the least cost and carbon significant elements responsible for less than $2 \%$ of the total CC and EC. Some of the remaining elements were identified as either carbon or cost hotspot which are vague in nature and have the potential to be become carbon or cost hotspots. Especially, Internal Finishes can be a cost and carbon significant element in high-end office buildings. The analysis clearly highlights the elements that need more focus during the design development which have high cost and carbon reduction potential over the others. Further, the hierarchy of cost and carbon significance of elements varies even between buildings with similar design features due to the difference in the specification. The comparison of element $\mathrm{CC}$ rates and element EC rates displays the complexity of achieving cost and carbon optimum design solutions.

Findings presented in the paper are based on two office buildings, and results might vary for buildings of different functions and classes. Hence, no inferences are drawn from the findings. However, the study has some key implications. The implication of carbon and cost significance analysis is that it informs 
designers about the elements whose design has high impact on the $\mathrm{CC}$ and $\mathrm{EC}$ of a particular type and class of building. For instance, $\mathrm{CC}$ and $\mathrm{EC}$ of the substructure of Building B was as twice as Building A due to an extra basement. Assuming that the basement is primarily for parking, if the likely EC and $\mathrm{CC}$ can be estimated during the early stages of design, then the design team can choose between one of the two options: (1) two basements or (2) one basement and private parking. There is clearly a tradeoff between the convenience of employees and savings in dual currency in those two options. Further, this analysis also helps identify the elements that can be disregarded during the early stages of design as its contribution to total EC and CC will be almost negligible, and no significant reduction can be achieved. In addition, the use of elemental $\mathrm{CC}$ and $\mathrm{EC}$ benchmarks to maximise the reduction was also highlighted though industry developed EC benchmarks does not exist at present. Hence, there is a need for industry developed EC benchmarks to facilitate dual currency management during early stages of design. Further, the 80:20 ratio could not be tested statistically due to the qualitative nature of the study. However, this study acts as a forerunner for the development and testing of prepositions and hypotheses on carbon significant elements of homogenous buildings with large samples. It is also believed that this study will facilitate life cycle cost and carbon analysis, which is a more holistic approach and superior to cradle-to-gate analysis though that could not be performed within the limited scope of the study.

\section{REFERENCES}

Ashworth, A. \& Perera, S. (2015), Cost studies of buildings, Oxon, Routledge.

Ashworth, A. \& Skitmore, R. M. (1983), Accuracy in Estimating, CIOB Occasional Paper No. 27. London: CIOB.

Atkins (2009),Towards a low cabon future changing the way we work today for a more sustainable tomorrow. UK.

Brandt, A. R. (2012), Variability and uncertainty in life cycle assessment models for greenhouse gas emissions from Canadian oil sands production, Environmental Science \& Technolog, 46, 1253-1261.

Clark, D. H. (2013), What Colour is your Building?: Measuring and reducing the energy and carbon footprint of buildings, UK, RIBA Enterprises Limited.

Cole, R. J. \& Kernan, P. C. (1996), "Life-cycle energy use in office buildings", Building and Environment, 31, 307-317.

Davies, P. J., Emmitt, S. \& Firth, S. K. (2014), Challenges for capturing and assessing initial embodied energy: a contractor's perspective, Construction Management and Economics, 32, 290-308.

Department for Environment Food \& Rural Affairs. (2015). Greenhouse gas conversion factor repository. Retrieved 23 July, 2015, from http://www.ukconversionfactorscarbonsmart.co.uk/

Fellows, R. and Lieu, A., 2003. Research methods for construction. 2nd ed. USA: Blackwell publishing.

Halcrow Yolles (2010), Sustainable offices - embodied carbon, South West Regional Development Agency.

Harling, K., 2002. Workshop. Annual meeting of the American Agricultural Economics Association, Case studies: their future role in agricultural and resource economics. 2009 July 27. California.

Hammond, G. \& Jones, C. (2011), A BSRIA guide Embodied Carbon The Inventory of Carbon and Energy (ICE), UK: BSRIA.

Hitchin, R. (2013), “CIBSE Research Report 9: Embodied Carbon and Building Services”, UK: CIBSE.

Koch, R. 2011. The 80/20 Principle, Nicholas Brealey Publishing.

Langston, Y. L. \& Langston, C. A. (2008), Reliability of building embodied energy modelling: an analysis of 30 Melbourne case studies, Construction Management and Economics, 26, 147160.

Lélé, S. M. (1991), Sustainable development: A critical review, World Development, 19, 607-621. 
Metz, B., Davidson, O. R., Bosch, P. R., Dave, R. \& Meyer, L. A. (2007), Climate Change 2007: Mitigation of Climate Change: Contribution of Working Group III to the Fourth Assessment Report of the Intergovernmental Panel on Climate Change, 2007. IPCC Fourth Assessment Report (AR4). Cambridge.

Monahan, J. \& Powell, J. C. (2011), An embodied carbon and energy analysis of modern methods of construction in housing: A case study using a lifecycle assessment framework, Energy and Buildings, 43, 179-188.

Munns, A. K. \& Al-Haimus, k. M. (2000), Estimating using cost significant global cost models, Construction Management and Economics, 18, 575-585.

RICS (2012), Elemental standard form of cost analysis principles, instructions, elements and definitions 4th (NRM) edition. London, UK: Building Cost Information Service.

RICS (2014), Methodology to calculate embodied carbon. 1 ed. UK: RICS.

Seeley, I. H. (1996), Building economics: appraisal and control of building design cost and efficiency, Basingstoke, Macmillan.

Shafiq, N., Nurrudin, M. F., Gardezi, S. S. S. \& Kamaruzzaman, A. B. (2015), Carbon footprint assessment of a typical low rise office building in Malaysia using building information modelling (BIM), International Journal of Sustainable Building Technology and Urban Development, 1-16.

Solomon, S., Qin, D., Manning, M., Chen, Z., Marquis, M., Averyt, K. B. \& Tignor, M. (2007), Climate Change 2007: The Physical Science Basis: Contribution of Working Group I to the Fourth Assessment Report of the Intergovernmental Panel on Climate Change. IPCC Fourth Assessment Report (AR4). Cambridge.

Sturgis Associates. (2010). Carbon profile: ropermark place. UK: Sturgis carbon profiling.

Tas, E. \& Yaman, H. (2005), A building cost estimation model based on cost significant work packages, Engineering, Construction and Architectural Management, 12, 251-263.

The Green Construction Board (2013), Low carbon routemap for the uk built environment. London: The Green Construction Board, WRAP, The Climate Centre and ARUP.

Victoria, M. F., Perera, S., Zhou, L., \& Davies, A. (2015a). Estimating Embodied Carbon: A dual currency approach. In Sustainable Buildings and Structures: Proceedings of the 1st International Conference on Sustainable Buildings and Structures, 29 October-1 November 2015, Suzhou, PR China, CRC Press, 223-230.

Victoria, M, Perera, S and Davies, A. (2015b) Developing an early design stage embodied carbon prediction model: A case study In: Raidén, A B and Aboagye-Nimo, E (Eds) Procs 31st Annual ARCOM Conference, 7-9 September 2015, Lincoln, UK, Association of Researchers in Construction Management, 267-276.

WRAP and UK Green Building Council. (2014). Embodied Carbon Database. Retrieved from: http://www.wrap.org.uk/content/embodied-carbon-database

YIN, R. K. 2014. Case study research design and methods, USA, Sage Publications. 